\title{
Pattern of Occlusal Contacts in Lateral Excursions (Canine Protection or Group Function)
}

\section{Sapkota B, ${ }^{1}$ Gupta $A^{2}$,}

\section{Department of Prosthodontist}

${ }^{1}$ Dhulikhel Hospital-Kathmandu University Hospital

Kathmandu University School of Medical Sciences Dhulikhel, Kavre, Nepal

${ }^{2}$ Dental Pearls Implants Centre

New Delhi, India

\section{Corresponding Author}

Binam Sapkota

Department of Dentistry

Dhulikhel Hospital-Kathmandu University Hospital

Kathmandu University School of Medical Sciences Dhulikhel, Kavre, Nepal

E-mail: sapkotabinam0@gmail.com

\section{Citation}

Sapkota B, Gupta A. Pattern of Occlusal Contacts in Lateral Excursions (Canine Protection or Group Function). Kathmandu Univ Med J 2014;45(1):43-47.

\section{ABSTRACT}

\section{Background}

Establishing or providing occlusion that successfully permits efficient masticatory function is basic to dentistry. To maintain harmony of the occlusal condition, the posterior teeth must pass close to but not contact their opposing teeth during mandibular movement. Anterior guidance is essential to a harmonious functional relationship in the masticatory system.

\section{Objective}

The objective of this study was to find out the frequency of pattern of occlusal contacts in lateral position and to compare the accuracy of shim-stock and articulating paper.

\section{Method}

This study was conducted in the Department of Prosthodontics, Kathmandu University School of Medical Sciences. The study consisted of 80 healthy subjects between the age group of 18-30 years. They were selected randomly from undergraduate students and dental hygienist of college of dental science and written consent was taken. This age was selected because of minimal occlusal wear.

\section{Results}

In the present study with 80 participants the majority of the contact patterns with shimstock on the working side were group function( $84 \%$ ), the canine protected occlusal patterns were found to be $12 \%$ and the unclassifiable pattern were found to be $4 \%$. On the otherhand, the data with articulating paper were group function type $(94 \%)$, the canine protected occlusal patterns as $2.5 \%$ and the unclassifiable pattern were found to be $3.5 \%$.

In this study, with shim stock, the majority of the contact patterns were group function being $84 \%$ whereas with the articulating paper it was $94 \%$. When shim stock occlusal strip (12 $\mu \mathrm{m}$ thick) was compared to commonly used articulating paper $(40 \mu \mathrm{m})$, the excessive thickness of articulating paper that exceed the maximum recommended thickness of occlusal recording strips markedly must have given much more false contacts.

\section{Conclusion}

It was concluded that the majority of the contact pattern were group function being $84 \%$ with shim stock and $94 \%$ with articulating paper. Also shim stock exhibits superior accuracy and reliability.

\section{KEY WORDS}

Canine guided, GPT, group function, nonworking side, unclassified pattern, working side. 


\section{INTRODUCTION}

Establishing or providing occlusion that successfully permits efficient masticatory function is basic to dentistry.

In health, the teeth functions in harmony with structures controlling the movement pattern of the mandible. Structures that determine these pattern are joints, muscles and teeth. ${ }^{1}$

To maintain harmony of the occlusal condition, the posterior teeth must pass close to but not contact their opposing teeth during mandibular movement. ${ }^{1}$

The long term stability of the posterior teeth is dependent on the anterior teeth not wearing away or moving, so it is important to establish an anterior guidance. ${ }^{1}$

Anterior guidance is essential to a harmonious functional relationship in the masticatory system. Anterior guidance can be categorized into three occlusal schemes: canine protection, group function and balanced occlusion. ${ }^{1}$ Canine protection and group function have been described as form of therapeutic occlusion in natural dentition.

In Glossary of Prosthodontic Terms 8 canine protection is defined as "a form of mutually protected articulation in which the vertical and horizontal overlap of the canine teeth disengage the posterior teeth in excursive movement of the mandible." Group function is defined as "multiple contact relation between maxillary and mandibular teeth in lateral movement on the working side.

The group function of the teeth on the working side distributes the occlusal load. The absence of contact on non-working side prevents those teeth from being subjected to the destructive obliquely directed forces found in non-working interferences. It also saves the centric holding cusps ie the mandibular buccal cusps and maxillary lingual cusps from excessive wear. The obvious advantage is the maintenance of the occlusion. ${ }^{2,3}$

Canine protection and group function have been used as categories for classification of the patterns of occlusal contacts in lateral excursion in natural dentition. ${ }^{4,5}$

Ink, silk ribbons with colorants, colored paper, plastic strips with colorants and wax have been used to visualize occlusal contacts. Dawson suggested that silk ribbon was the most efficient Halperin et al studied marking material to determine thickness, strength and plastic deformation and concluded that occlusal registration strips should be less than $21 \mu \mathrm{m}$ thick. ${ }^{1,6}$

\section{METHODS}

This study was conducted in the Department of Prosthodontics, KUSMS. The study design was randomized qualitative study. The study consisted of 80 healthy subjects between the age group of 18-30 years. They were selected from undergraduate students and dental hygienist of college of dental science and written consent was taken.
This age was selected as less of occlusal wear is seen in this age group.

GC Articulating paper of $40 \mu$ and Bausch Shim stock of $12 \mu$ was used in this study.

The interocclusal contacts were recorded using articulating paper and shimstock. Each subject was required to sit upright in a dental chair with the Frankfurt horizontal plane almost horizontal.

The articulating paper and shim-stock was placed simultaneously on the occlusal surface of the right side, most posterior mandibular molar, and the subject was requested to close his/her mandible to the maximum intercuspation.

With a constant pulling force maintained on the articulating paper and shim-stock, the subject was requested to perform a habitual gliding movement to the right with the teeth in light contact for the working side contact.

The nonworking side contacts were examined when the articulating paper and shim-stock were placed one by one on the occlusal surfaces of mandibular posterior teeth on left side and the subject was asked to move the mandible towards the right side.

After the movement the occlusal contact patterns were examined.

\section{RESULTS}

In the present study, a total of 80 subjects were taken as a study group in which age range from 18 to 30 years. Each subject was required to sit upright in a dental chair with the Frankfurt horizontal plane almost horizontal. Contact pattern was recorded for both working and non-working side.

Table 1, 2 and fig 1 shows the intergroup comparison of different occlusal contact pattern using articulating paper and shim stock at working side. This shows canine guided was $12 \%$ (with shim stock) to $2.5 \%$ (using articulating paper) with probability level value ( $p$ value) 0.04 that was statistically significant whereas group function increased from $84 \%$ with shim stock to $94 \%$ with articulating paper here $p$-value was 0.03 which was also significant. However the unclassified pattern decreased from $4 \%$ to $3.5 \%$ with p-value 0.05 and was not significant.

Table 1. Distribution of occlusal contact pattern on working side using articulating paper found to be group function, then canine guided and the unclassified classification.

\begin{tabular}{|lcc|}
\hline Group of contact pattern & $\begin{array}{c}\text { Number of contact } \\
\text { pattern }\end{array}$ & Percentage \\
\hline Group function & 75 & 94 \\
\hline Canine guided & 2 & 2.5 \\
\hline Unclassified & 3 & 3.5 \\
\hline Total & 80 & 100 \\
\hline
\end{tabular}


Table 2. Distribution of occlusal contact pattern on working side using shim-stock found to be group function, then canine guided and the unclassified classification.

\begin{tabular}{|lcc|}
\hline Group of contact pattern & $\begin{array}{c}\text { Number of contact } \\
\text { pattern }\end{array}$ & Percentage \\
\hline Group function & 67 & 84 \\
\hline Canine guided & 10 & 12 \\
\hline Unclassified & 3 & 4 \\
\hline Total & 80 & 100 \\
\hline
\end{tabular}

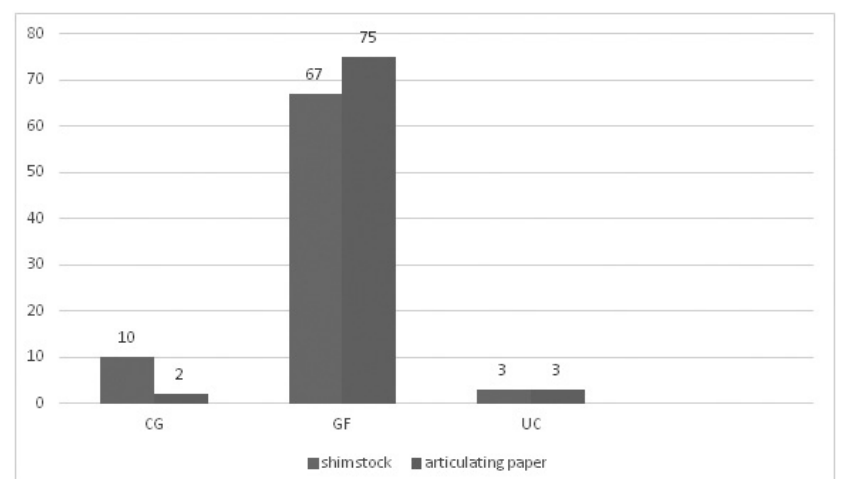

Figure 1. Intergroup comparison of occlusal contact pattern using shim stock and articulating paper.(CG - Canine Guided, GF - Group Function, UC - Unclassifiable Pattern.

Table 3, 4 and fig 2 shows intergroup comparison of occlusal contact pattern at non-working side using articulating paper and shim stock. Here the canine guided was $7 \%$ with shim stock and was reduced to $4 \%$ with articulating paper with $p$-value 0.04 which was significant. Whereas, for group function with shim stock it was $87 \%$ which was reduced to $80 \%$ using articulating paper and here also $p$-value is 0.04 and is significant. Similarly for unclassified pattern also it is significant with $\mathrm{p}$-value 0.03 .

Table 3. Distribution of occlusal contact pattern on non-working side using articulating paper.

\begin{tabular}{|lcc|}
\hline Group of contact pattern & $\begin{array}{c}\text { Number of contact } \\
\text { pattern }\end{array}$ & Percentage \\
\hline Group function & 64 & 80 \\
\hline Canine guided & 3 & 4 \\
\hline Unclassified & 13 & 16 \\
\hline Total & 80 & 100 \\
\hline
\end{tabular}

Table 4. Distribution of occlusal contact pattern on non-working side using shim-stock.

\begin{tabular}{|lcc|}
\hline Group of contact pattern & $\begin{array}{c}\text { Number of contact } \\
\text { pattern }\end{array}$ & Percentage \\
\hline Group function & 70 & 87 \\
\hline Canine guided & 6 & 7 \\
\hline Unclassified & 4 & 6 \\
\hline Total & 80 & 100 \\
\hline
\end{tabular}

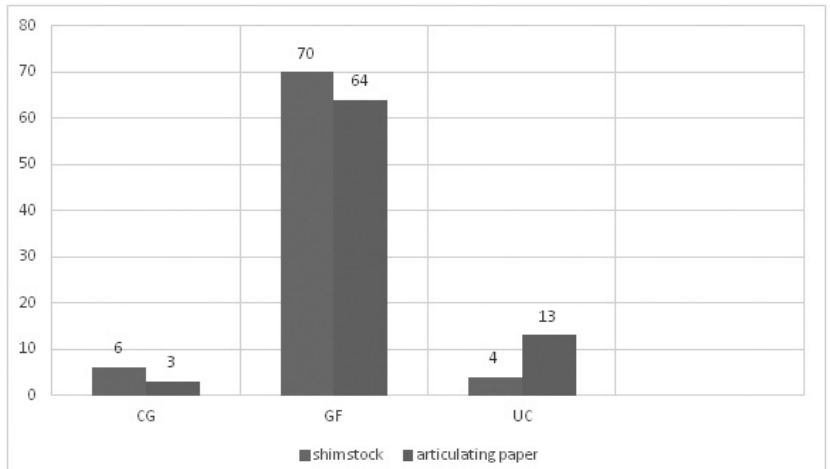

Figure 2. Intergroup comparison of occlusal contact pattern using shim stock and articulating paper (CG - Canine Guided, GF - Group Function, UC - Unclassifiable Pattern.

\section{DISCUSSION}

Biological variation is a characteristic of life. Some genetic variations are general in the dentition, whereas others include environmental and affect particular tooth form, morphology and function. Canine protection and group function have been used as categories for classification of the patterns of occlusal contacts in lateral excursions in natural dentition.

In The Glossary of Prosthodontic Terms, canine protection is defined as "a form of mutually protected articulation in which the vertical and horizontal overlap of the canine teeth disengages the posterior teeth in the excursive movements of the mandible." " Group function is defined as "multiple contact relations between the maxillary and mandibular teeth in lateral movements on the working side." However, the occlusal contact pattern varies according to the mandibular position examined. There is no description regarding the mandibular position when examining occlusal contacts, which may account for the inconsistencies among the findings of the previously done studies.

In the present study 80 participants from 18 to 30 years of age were chosen from KUSMS College of Dental science. This age group was selected, as by this age all the permanent teeth would have erupted and the amount of age changes would be less. In this age group, attrition is very less so we can have the precise idea of occlusal contacts.

In a review of canine protection and group function, Thornton1 stated that there is no scientific evidence that supports one contact pattern over the other. ${ }^{8}$ Nevertheless, a precise and reproducible method for determining the occlusal contact and classifying the occlusal contact patterns has not been established yet. The establishment of a new classification system for occlusal contact pattern could resolve these disagreements and clarify the impact of the occlusal contact patterns that contribute to the success of restorative dentistry and in the prevention and treatment of TMD.

In many studies of occlusal contact patterns, the occlusal contacts have been recorded in an edge-to-edge position 
of the canines approximately $3 \mathrm{~mm}$ lateral from the maximum intercuspation, or in an unregulated position. But this position is rarely used during mastication except in incising food and in parafunction such as bruxism. ${ }^{9-11}$

However, it is highly possible that the occlusal contact during mastication occurs only within the $1 \mathrm{~mm}$ lateral position, depending on the person. Yaffe A, Ehrlich J as well as Ogawa etal suggested that occlusal gliding contact during mastication would occur in the $0.5 \mathrm{~mm}$ position and that the occlusal contact pattern in this position must be evaluated when investigating the role of occlusal contact on masticatory function. ${ }^{12,13}$

Therefore, in this study, occlusal contacts were examined in approximately $0.5-1 \mathrm{~mm}$ lateral positions.

A comparative study has shown that shim stock has better reliability than articulating film for examining occlusal contacts, and that shim stock provides acceptable reliability in the clinical measurement of occlusal contacts. ${ }^{9}$ To obtain the reliability of contact recording, the current study standardized the factors that affect the results of occlusal contact, such as head posture diurnal effects. ${ }^{14,15}$ To rule out the diurnal variation error, all measurements were taken from 9a.m. to 11a.m. in the morning.

Shim stock occlusal registration strips as well as articulating paper was evaluated for relative reliability in recording occlusal contacts. Thickness, strength and the plastic deformation of occlusal registration strips have been identified as the most important requirements to identify the occlusal contacts by Halperin et al. ${ }^{6} \mathrm{~A}$ thin occlusal strip has many advantages as it is below the occlusal thickness perception level of most patients. It has been advocated that the thickness of occlusal registration strips should be within the range of 13 to $21 \mu \mathrm{m}$ thick to locate working and balancing interferences. A thick occlusal registration strip has two major disadvantages: (1) it can indicate tooth contact between opposing teeth when no teeth contact exists if the thickness of the registration strips is greater than the space between the teeth and (2) it can introduce a proprioceptive response that in turn can cause the jaw to be deflected.

Occlusal registration strips also should have enough plastic deformation before they tear, enabling the dentist to evaluate the occlusal contact. All paper strips are usually brittle. Paper strips are contra indicated as it shreds and tears when wet, which makes it an impractical material for evaluating occlusion intraorally. The metallic foils and Mylar strips are unaffected by wetness. Another important character of the occlusal strip is the marking ability and it should be non-smearing and non-smudging in wet environment with precise marking ability to be effective for intraoral occlusal markings. ${ }^{6}$

In this study, with shim stock, the majority of the contact patterns with shim stock were group function being $84 \%$ whereas with the articulating paper it was $94 \%$. When shim stock occlusal strip ( $12 \mu \mathrm{m}$ thick) was compared to commonly used articulating paper $(40 \mu \mathrm{m})$, the excessive thickness of articulating paper that exceed the maximum recommended thickness of occlusal recording strips markedly must have given much more false contacts when the gap between opposing teeth was less than the thickness of paper itself. Similarly the brittle nature of articulating paper without any plastic deformation ability and being moisture sensitive in the oral environment that subsequently get smeared and smudged made the articulating paper very fallacious in recording the occlusal contacts. Hence, the shim stock occlusal strip with minimum thickness, better plastic deformation and tensile strength as well as its water resistant nature and precise marking ability, seemed to have better reliability for examining occlusal contacts during lateral excursion than the articulating paper. ${ }^{6}$

In this present study, the majority of the contact patterns on the working side were group function (84\%), the canine protected occlusal patterns were found to be $12 \%$ and the unclassifiable pattern were found to be $4 \%$ whereas with the articulating paper it was group function type (94\%), the canine protected occlusal patterns as $2.5 \%$ and the unclassifiable pattern were found to be $3.5 \%$.

In light of the given definition, canine guided and group function appears to imply an ideal therapeutic occlusion and is not a usable description for an existing contact pattern. In contrast, some studies that examined several positions outside the $1 \mathrm{~mm}$ position reported a low prevalence of canine protection. ${ }^{16,17}$

The current results demonstrated greater prevalence of canine protection compared with those studies. The disparity among these findings seems to be due to the differences in registration material, age, type of occlusion (such as Angle classification), and gender of the subjects. ${ }^{17}$

The findings in this study revealed a group of contact patterns that were unclassifiable by the system categorizing guidance patterns that used only canine protection and group function. A new classification system of occlusal guidance should be established: otherwise any theory regarding prosthetic treatment and/or occlusion will be ambiguous.

\section{CONCLUSION}

The result for classification system in working side using articulating paper where majority of the contact patterns were group function type (94\%), the canine protected occlusal patterns $2.5 \%$ and the unclassifiable pattern were found to be $3.5 \%$.

The result for classification system in nonworking side using articulating paper where the canine protected occlusal pattern was found to be ( $4 \%$ ) whereas the group function $(80 \%)$, and unclassified contact patterns were found to be $16 \%$. 
The result for classification system in working side using shim stock majority of the occlusal contact patterns were found to be group function ( $84 \%$ ) followed by the canine protected occlusal patterns which were found to be $12 \%$ and the unclassifiable pattern were $4 \%$.

\section{REFERENCES}

1. The envelope of function. In, Dawson PE (ed.), Functional occlusion from TMJ to smile design. 1st edition. Canada; Mosby Elsevier: 2007. pg. 141-8.

2. Fundamentals of occlusion. In, Shillinberg HT, Hobo S, Whitsett LD, Jacobi R, Brackett SE (ed.), Fundamentals of Fixed Prosthodontics. 3rd edition. U. S. A.; Quintessence Publishing CO: 1997. pg. 11-24.

3. Principles of Occlusion. In, Rosensteil S, Land MF, Fujimoto J (ed.), Contemporary Fixed Prosthodontics. 3rd edition. U. S. A.; Harcout Brace \& Co: 2001. pg. 83-107.

4. Ogawa T, Ogimoto T, Koyano K. Pattern of occlusal contacts in lateral positions. Canine protection and group function validity in classifying guidance pattern. J Prosthet Dent 1998. Jul; 80(1):67-74.

5. Ogawa T, Ogimoto T, Koyano K. The relationship between nonworking side occlusal contacts and mandibular position. J Oral Rehab 2001 Oct; 28(10):976-81

6. Halperin GC, Halperin AR, Norling BK. Thickness, strength and plastic deformation of occlusal registration strips. J Prosthet Dent. 1982 Nov; 48(5):575-8.

7. Glossary of Prosthodontic terms. The academy of Prosthodontics. 8th edition. pg-57.

8. Thornton LJ. Anterior guidance: group function/canine guidance. A literature review. J Prosthet Dent. 19900ct; 64(4):479-82.

9. Takai A, Nakano M, Bando E, Hewlett ER. Evaluation of three occlusal examination methods used to record tooth contacts in lateral excursive movements. J Prosthet Dent. 1993 Dec; 70(6):500-5.
The result for classification system in nonworking side using shim stock where the canine protected occlusal pattern was found to be $7 \%$ whereas the group function (87\%), and unclassifiable occlusal contact patterns found to be $6 \%$.

Shim stock exhibits superior accuracy and reliability as compared to the articulating paper.

10. Woda A, Vigneron P, Kay D. Nonfunctional and functional occlusa contacts: A review of the literature. J Prosthet Dent. 1979 Sep; 42(3):335-41.

11. Agerberg G, Sandstrom R. Frequency of occluslal interferences: A clinical study in teenagers and young adults. J Prosthet Dent. 1988 Feb; 59(2):212-7.

12. Yaffe A, Ehrlich J. The functional range of tooth contact in lateral gliding movements. J Prosthet Dent. 1987 Jun; 57(6):730-3.

13. Koyano K, Ogawa T, Suetsugu T. The influence of canine guidance and condylar guidance on mandibular lateral movements. J Oral Rehab 1997 Nov; 24(11):802-7.

14. Yamada R, Ogawa T, Koyano K, Suetsugu T. effect of head posture on the direction and stability of mandibular closing movement. J Oral Rehabil. 1999Jun;26(6):511-20

15. Berry DC, Singh BP. Daily variation in occlusal contacts. J Prosthet Dent 1983 Sep; 50(3):386-91.

16. Ingervall B, Hahner R, Kessi S. Pattern of tooth contacts in eccentric mandibular positions in young adults. J Prosthet Dent. 1991 Aug; 66(2):169-76.

17. Ingervall B, Meyer D, Stettler B. Tooth contacts in eccentric mandibular positions and facial morphology. J Prosthet Dent. 1992 Mar; 67(3):317-22. 